\title{
Damage evolution in a self-healing air plasma sprayed thermal barrier coating containing self-shielding MoSi 2 particles
}

DOI:

10.1111/jace. 16313

\section{Document Version}

Accepted author manuscript

Link to publication record in Manchester Research Explorer

Citation for published version (APA):

Chen, Y., Zhang, X., van der Zwaag, S., Sloof, W., \& Xiao, P. (2019). Damage evolution in a self-healing air plasma sprayed thermal barrier coating containing self-shielding MoSi 2 particles. Journal of the American Ceramic Society, 4899-4910. https://doi.org/10.1111/jace.16313

\section{Published in:}

Journal of the American Ceramic Society

\section{Citing this paper}

Please note that where the full-text provided on Manchester Research Explorer is the Author Accepted Manuscript or Proof version this may differ from the final Published version. If citing, it is advised that you check and use the publisher's definitive version.

\section{General rights}

Copyright and moral rights for the publications made accessible in the Research Explorer are retained by the authors and/or other copyright owners and it is a condition of accessing publications that users recognise and abide by the legal requirements associated with these rights.

\section{Takedown policy}

If you believe that this document breaches copyright please refer to the University of Manchester's Takedown Procedures [http://man.ac.uk/04Y6Bo] or contact uml.scholarlycommunications@manchester.ac.uk providing relevant details, so we can investigate your claim.

\section{OPEN ACCESS}


Damage evolution in a self-healing air plasma sprayed thermal barrier coating containing selfshielding $\mathrm{MoSi}_{2}$ particles

Ying Chen ${ }^{1, *}$, Xun Zhang ${ }^{1}$, Sybrand van der Zwaag ${ }^{2}$, Willem G. Sloof ${ }^{3}$ and Ping Xiao ${ }^{1,4 \dagger}$

${ }^{1}$ School of Materials, University of Manchester, Manchester, M13 9PL, UK

${ }^{2}$ Novel Aerospace Materials group, Faculty of Aerospace Engineering, Delft University of Technology, Kluyverweg 1, 2629 HS, Delft, The Netherlands

3 Department of Materials Science and Engineering, Delft University of Technology, Mekelweg 2, 2628 CD Delft, The Netherlands

${ }^{4}$ Shanghai Key Laboratory of Advanced High-Temperature Materials and Precision Forming, Shanghai Jiao Tong University, Shanghai, 200240, PR China

\section{Abstract}

A self-healing thermal barrier coating (TBC) system is manufactured by air plasma spraying (APS) and tested by thermal cycling. The ceramic topcoat in the self-healing APS TBC system consists of an yttria stabilised zirconia (YSZ) matrix and contains self-shielding aluminium containing $\mathrm{MoSi}_{2}$ healing particles dispersed close to the topcoat/bond coat interface. After spraying the healing particles the material was annealed to promote the formation of an oxygen impermeable $\mathrm{Al}_{2} \mathrm{O}_{3}$ shell at the $\mathrm{MoSi}_{2}$-TBC interfaces by selective oxidation of the aluminium fraction. The samples were subsequently thermally cycled between room temperature and $1100{ }^{\circ} \mathrm{C}$. The study focussed on the spontaneous formation of the $\mathrm{Al}_{2} \mathrm{O}_{3}$ shell as well as the subsequent damage evolution in the APS produced TBC during thermal cycling.

${ }^{\dagger}$ Corresponding author: Ping Xiao (p.xiao@manchester.ac.uk).

* Present address: OxMet Technologies, Begbroke Science Park, Oxfordshire, OX5 1PF, United Kingdom

This article has been accepted for publication and undergone full peer review but has not been through the copyediting, typesetting, pagination and proofreading process, which may lead to differences between this version and the Version of Record. Please cite this article as doi: $10.1111 /$ jace. 16313

This article is protected by copyright. All rights reserved. 
Experimental evidence showing characteristic signs of crack healing in the topcoat is identified and analysed. The study shows that while the concept of the self-healing APS TBCs containing self-shielding $\mathrm{MoSi}_{2}$ particles is promising, future study is needed to improve the protectiveness of the $\mathrm{Al}_{2} \mathrm{O}_{3}$ shells by further tailoring the aluminium content in the $\mathrm{MoSi}_{2}$ and the particle shape to avoid the premature oxidation of the healing particles and maximise crack healing efficiency.

Keywords: APS TBC, Self-healing; Thermal cycling; Oxidation, Self-shielding. Alcontaining $\mathrm{MoSi}_{2}$.

\section{Introduction}

Air plasma sprayed thermal barrier coatings (APS TBCs) are widely used in gas-turbine engines to protect the thermally loaded components against hot gases and increase engine durability as well as reliability ${ }^{1-3}$. A typical state-of-the-art APS TBC system consists of a refractory-oxide ceramic topcoat (typically made of 7-8 wt.\% yttria stabilised zirconia (YSZ)) and a $\mathrm{MCrAlY}(\mathrm{M}=\mathrm{Ni}$, Co or $\mathrm{Ni} / \mathrm{Co})$ bond coat deposited on a superalloy substrate. Unfortunately, the APS TBCs undergo spallation failure of the ceramic topcoats after service at high temperatures for a certain period of time as a result of thermal stressed, leaving the bare metal exposed to the corrosive hot gases. The failure of the TBCs mainly occurs at the base of the topcoat near the topcoat/bond coat interface, driven by the stress induced by the thermal mismatch between the ceramic layers and metal during cooling from the service temperature ${ }^{1,4,5}$.

This article is protected by copyright. All rights reserved. 
To extend the lifetime of APS TBCs under thermal cycling conditions, Sloof et al. have recently proposed a concept of self-healing APS TBCs ${ }^{6,7}$, in which $\mathrm{MoSi}_{2}$ based 'healing' particles are integrated into the topcoat close to the topcoat/bond coat interface (where cracking and delamination mainly occurs). It is envisaged that when microcracks growing in the $\mathrm{TBC}$ during exposure to high temperature air intersect the healing particles, the fractured healing particles will oxidise leading to formation of vitreous and glassy $\mathrm{SiO}_{2}$, which is promoted by addition of a small amount boron. Due to the amorphous nature and the volume expansion (about $138 \%{ }^{8}$ ) associated with the oxidation, this $\mathrm{SiO}_{2}$ is able to flow into the microcracks and infiltrate a significant portion of the crack length. Subsequently, the $\mathrm{SiO}_{2}$ expelled into the crack reacts with the surrounding YSZ topcoat matrix to form load-bearing crystalline zircon $\left(\mathrm{ZrSiO}_{4}\right)$, which re-establishes the adhesion of the cracked surfaces and restores the structure integrity of the topcoat. However, as YSZ is a fast-ion oxygen conductor $^{9,10}$ and the interconnected porosity in the APS TBC allows easy ingress of oxygen, it is to be expected that bare $\mathrm{MoSi}_{2}$ healing particles would suffer from premature oxidation even in the absence of thermally induced microcracks leading to a loss of crack healing capability during long-term thermal exposure even in the absence of damage. Therefore, it is necessary to coat $\mathrm{MoSi}_{2}$ healing particles with a protective shell. It has been suggested that $\alpha-\mathrm{Al}_{2} \mathrm{O}_{3}$ might be an ideal candidate material for the protective shell due to its impermeability for oxygen ${ }^{11,12}$ and its thermodynamic compatibility with YSZ (they do not form interphases and their mutual solubility is very limited ${ }^{13}$, which ensures their mutual stability during long-term thermal exposure). Furthermore, the $\alpha-\mathrm{Al}_{2} \mathrm{O}_{3}$ has a good mechanical bonding to both the TBC matrix material. Provided the shell is fully dense and covers the entire particle, the encapsulation ensures that the healing particles are oxidised at a minimal rate during normal service conditions and a sufficient amount of $\mathrm{Si}$ remains available for crack healing when the particles are intersected by a crack. 
While the feasibility of the self-healing APS TBCs seems clear, experimental work is needed to validate the concept and provide feedback to optimise the material design and processing techniques. The simplest approach would be to pre-coat the $\mathrm{MoSi}_{2}$ particles and then to deposit the coated particles in the TBC near the interface with the bond coat. Carabat et al. have shown that the $\mathrm{MoSi}_{2}$ particles could be successfully encapsulated within a continuous and dense $\mathrm{Al}_{2} \mathrm{O}_{3}$ shell via a precipitation process ${ }^{14}$ or sol-gel method ${ }^{15}$. A study of a model self-healing TBC system manufactured by spark plasma sintering (SPS) has indeed shown a prolonged lifetime as a result of the proposed crack healing mechanism during thermal cycling ${ }^{16}$. However, the deposition and consolidation conditions as used during the production of the composite TBC via SPS are much milder than those encountered during the most common industrial process used for TBC deposition: the APS process. Koch et al. have shown that the problems of differences in melting point and volatility between the YSZ and the $\mathrm{MoSi}_{2}$ particles can be overcome by a dual injection procedure ${ }^{17}$. With their optimised technique it was possible to deposit a sound and heterogeneous TBC system in which the layer closest to the bond coat contained about $10 \%$ healing particles while the layers closest to the free surface were free of healing particles. However, when spraying conventional $\mathrm{MoSi}_{2}$ particles the particles thus deposited would be unprotected against premature oxidation. To overcome this problem, the option of pre-alloying the $\mathrm{MoSi}_{2}$ with aluminium was explored assuming that due to preferential oxidation the pre-alloyed particles would form a dense $\alpha-\mathrm{Al}_{2} \mathrm{O}_{3}$ layer near the particle-TBC matrix autonomously during a pre-oxidation treatment of the deposited composite material. Recent research using $\mathrm{MoSi}_{2}$ particle containing 2, 6 or $12 \mathrm{wt} \%$ aluminium showed that the concept of self-shielding indeed worked well, albeit best for the higher Al concentrations.

In this work, a study on a complete self-healing TBC system manufactured by APS with all original design features (e.g. APS deposition, self-shielding healing particles) incorporated is 
presented for the first time. The focus of the work is the evolution of the Al-alloyed $\mathrm{MoSi}_{2}$ healing particles and their interaction with the YSZ topcoat matrix during thermal cycling, which are essential to the realisation of the successful crack healing.

\section{Materials and Methods}

\subsection{Manufacturing of the self-healing APS TBCs}

YSZ (8wt $\% \mathrm{Y}_{2} \mathrm{O}_{3}$, H.C. Starck GmbH, Goslar, Germany) powder and 12 wt\% Al-containing $\mathrm{MoSi}_{2}$ particles (ChemPur, Germany) including $1.8 \mathrm{wt} \% \mathrm{~B}$ were used for topcoat materials.

The YSZ-MoSi $i_{2}$ composite topcoats were deposited onto the Hastelloy® $\mathrm{X}$ superalloy substrate buttons (having a diameter of $25.4 \mathrm{~mm}$ and a thickness of $6 \mathrm{~mm}$ ) using a dual particle feed APS system. More details about the spraying process could be found elsewhere 17. Rather than manufacture a topcoat with $\mathrm{MoSi}_{2}$ particles distributed homogenously throughout the entire coating, the $\mathrm{MoSi}_{2}$ particles were deposited exclusively in the regions close to the interface where cracking and delamination predominately occur. This design not only maximised the probability for the particles to intersect with the propagating cracks and involve in subsequent crack healing, but also minimised the effect of healing particles on the overall properties (e. g. coefficient of thermal expansion (CTE), thermal conductivity and stiffness) of the topcoat ${ }^{18,19}$. The volume fraction of the $\mathrm{MoSi}_{2}$ particles embedded in the YSZ topcoat near the interface is about 10 vol.\%. Prior to topcoat deposition, a NiCoCrAlY (Amdry 365-2, Sulzer Metco, USA) bond coat with a thickness of about $200 \mu \mathrm{m}$ was applied by vacuum plasma spraying onto the superalloy substrate. After deposition of the topcoats, the coated superalloy buttons are annealed at $1100{ }^{\circ} \mathrm{C}$ in argon with a low oxygen partial pressure (about $1 \times 10^{-14} \mathrm{~Pa}$ ) for 16 hours to grow $\mathrm{Al}_{2} \mathrm{O}_{3}$ shells around the healing particles through selective oxidation of the $\mathrm{Al}$ alloyed in $\mathrm{MoSi}_{2}$. This low oxygen partial pressure was 
realised by mixing pure argon with a fixed hydrogen water vapour ratio which is controlled by measuring the dew point. More details about this method could be found elsewhere ${ }^{20}$. The oxygen can readily access the embedded alloyed $\mathrm{MoSi}_{2}$ particles, since the YSZ top coat has an interconnected network of pores ${ }^{21-23}$ (about 20 vol.\%) and even the diffusion of oxygen through the YSZ itself is relatively fast ${ }^{24}$.

\subsection{Thermal cycling}

The self-healing APS TBCs samples were thermally cycled in laboratory air between room temperature and $1100{ }^{\circ} \mathrm{C}$ in a $\mathrm{CM}^{\mathrm{TM}}$ automatic rapid cycle furnace. Each cycle consisted of 10 minutes ramping, 90 minutes "hot time" at $1100{ }^{\circ} \mathrm{C}$ and 10 minutes fan-assisted air quenching. Some samples were removed from the furnace at specific intervals for further characterisation.

\subsection{Characterisation}

The microstructures and compositions of cross-sectioned samples were examined using an optical microscope (Olympus BH2-UMA) and a scanning electron microscope (Sigma, Zeiss) fitted with an energy dispersive X-ray spectroscopy system (EDS, X-MaxN 50 SDD, Oxford Instruments). All samples were first impregnated with a low-viscosity epoxy resin to retain the original integrity of the samples, especially the thermally-cycled samples, and eliminate artificial damages introduced during sample preparation. The high wettability and low viscosity of the resin allow it to fully infiltrate into open porosities. After complete solidification of the resin, the samples were cross-sectioned using a SiC abrasive cutting blade in a precision cut-off machine (Accutom 10, Struers), followed by grinding and polishing to a mirror finish.

This article is protected by copyright. All rights reserved. 
In order to study the microstructure and composition of the healing particles in greater details, thin lamellae of the healing particles were prepared by a focused ion beam (FIB, Helios NanoLab 660, FEI) and analysed using a transmission electron microscope (TEM, Titan G2 ChemiSTEM, FEI) equipped with a Super-X EDS system. The TEM was mainly operated in high-angle annular dark field scanning transmission electron microscopy (HAADF-STEM) mode, which gave atomic number contrast and facilitate chemical analysis. TEM samples were obtained by FIB milling across the interfaces between the YSZ topcoat matrix and the $\mathrm{MoSi}_{2}$ healing particles. The lamellae were then lifted out and welded to a copper grid using a combination of an OmniProbe micromanipulator and a gas injection system fitted in the FIB system, followed by thinning to electron transparent thickness $(<100$ $\mathrm{nm})$. More details of the TEM sample preparation can be found elsewhere ${ }^{25}$. To complement the TEM analysis, the thin lamellae were further analysed using transmission Kikuchi diffraction (TKD) in an extreme high-resolution SEM (Magellan 400 XHRSEM, FEI) mapping the crystallographic phase across the YSZ/MoSi 2 interface. The transmission geometry adopted in the TKD technique allows a minimum interaction volume between the impinging electrons and the sample, and therefore, improves the spatial resolution over the conventional electron backscattered diffraction ${ }^{26}$.

\section{Results and discussion}

\subsection{Microstructure of the as-deposited and annealed self-healing TBCs}

An optical image of the cross-section of an as-deposited and annealed self-healing APS TBC is shown in Fig.1. The thickness of the topcoat is $\sim 500 \mu \mathrm{m}$, varying slightly between $\sim 480$ and $\sim 520 \mu \mathrm{m}$ from place to place over the cross-section due to the extensive surface and interface roughness. As intended the $\mathrm{MoSi}_{2}$ particles (the light contrast) are dispersed in the 
YSZ topcoat matrix near the topcoat/bond coat interface, with a maximum distance of $\sim 180$ $\mu \mathrm{m}$ away from the interface. Many of the healing particles shows a "splat" shape (tens of microns in length and a few microns in width), which is a characteristic feature of the microstructure of coatings deposited by APS, but a number of particles had retained their original powder shape.

\subsection{Microstructure and chemistry of the healing particles in the as-deposited and annealed self-healing TBCs}

A backscattered electron (BSE) image of two $\mathrm{MoSi}_{2}$ healing particles in an as-deposited and annealed and a pre-treated self-healing TBC with the corresponding EDS maps are shown in Fig.2. It should be noted that due to the subtle difference in atomic numbers between YSZ and $\mathrm{MoSi}_{2}$, the contrast between these two materials is weak and they are virtually indistinguishable. The EDS map of $\mathrm{Al}$ shows that there are thin, continuous Al-rich layers along the perimeters of the particles, suggesting successful formation of $\mathrm{Al}_{2} \mathrm{O}_{3}$ shells around the particles.

A HAADF-STEM image of a $\mathrm{MoSi}_{2}$ healing particle in an as-deposited and annealed selfhealing TBC is shown in Fig.3a. The differences in element contrast in the HAADF-STEM image, combined with the corresponding EDS maps (Figs 3b-e) confirm the successful in-situ encapsulation of the healing particle by an $\mathrm{Al}_{2} \mathrm{O}_{3}$ shell. Selected area election diffraction (SEAD) analysis of the $\mathrm{Al}_{2} \mathrm{O}_{3}$ shell failed due to the extremely fine grain size. However, high resolution TEM analysis of the $\mathrm{Al}_{2} \mathrm{O}_{3}$ shell reveals a typical corundum structure (see Fig.3f), suggesting that the shell is mainly composed of $\alpha-\mathrm{Al}_{2} \mathrm{O}_{3}$ grains. The thickness of the $\mathrm{Al}_{2} \mathrm{O}_{3}$ shell is not uniform, varying between $\sim 230$ and $\sim 320 \mathrm{~nm}$ from place to place in most parts of the shell. However, in some regions the thickness of the $\mathrm{Al}_{2} \mathrm{O}_{3}$ shell did reach $\sim 2 \mu \mathrm{m}$. 
Furthermore, it is seen that there are fine, secondary-phase inclusions (brighter contrast) in many parts of the $\mathrm{Al}_{2} \mathrm{O}_{3}$ shell, with the thickest section containing the highest amount of inclusions. A more detailed examination given by a higher magnification HAADF-STEM image (Fig.4a) and corresponding EDS maps (Fig.4b-e) suggests that these finely dispersed inclusions are YSZ grains. The microstructure of the $\mathrm{Al}_{2} \mathrm{O}_{3}$ shell is very similar to that of the mixed $\mathrm{Al}_{2} \mathrm{O}_{3} / \mathrm{YSZ}$ zone in the thermally grown oxide (TGO) observed in electron beam physical vapour deposited TBC systems ${ }^{27-29}$, which are believed to result from dissolution of the YSZ matrix in the initially grown metastable $\mathrm{Al}_{2} \mathrm{O}_{3}$ (having a high solubility for $\mathrm{ZrO}_{2}$ and $\mathrm{Y}_{2} \mathrm{O}_{3}$ ) and the subsequent precipitation when the metastable $\mathrm{Al}_{2} \mathrm{O}_{3}$ transformed to $\alpha-\mathrm{Al}_{2} \mathrm{O}_{3}$ (having a limited solubility for $\mathrm{Y}_{2} \mathrm{O}_{3}$ and $\mathrm{ZrO}_{2}$ ). The presence of these $\mathrm{YSZ}$ inclusions in the $\mathrm{Al}_{2} \mathrm{O}_{3}$ shell could be detrimental to the protection of the shell as YSZ has high oxygen diffusivities at high temperature as it might provide fast inward diffusion paths for oxygen. This is probably the reason for the existence of the abnormally high thickness in some parts of the $\mathrm{Al}_{2} \mathrm{O}_{3}$ shell where a large number of YSZ inclusions is seen. A combination of selected area diffraction (Fig.3g and h) and EDS mapping (Fig.3b-e) shows that the encapsulated healing particle comprises a tetragonal $\mathrm{MoSi}_{2}$ core and a thin, outer tetragonal $\mathrm{Mo}_{5} \mathrm{Si}_{3}$ layer ( $\sim 260$ to $\sim 920 \mathrm{~nm}$ thick) in contact with the $\mathrm{Al}_{2} \mathrm{O}_{3}$ shell. The formation of this $\mathrm{Mo}_{5} \mathrm{Si}_{3}$ layer is attributed to the evaporation of $\mathrm{Si}$ from the $\mathrm{MoSi}_{2}$ healing particles during thermal spraying. Pores are seen in the $\mathrm{Mo}_{5} \mathrm{Si}_{3}$ layer as well at the interface between the $\mathrm{Al}_{2} \mathrm{O}_{3}$ shell and the $\mathrm{Mo}_{5} \mathrm{Si}_{3}$ layer.

Assuming all dissolved aluminium to be consumed in the formation of the $\mathrm{Al}_{2} \mathrm{O}_{3}$ shell via selective oxidation the thickness of the $\mathrm{Al}_{2} \mathrm{O}_{3}$ shell produced should vary with the particle size. To predict the dependence of the $\mathrm{Al}_{2} \mathrm{O}_{3}$ shell thickness on the particle size, it is assumed that the particle has a spherical shape with a radius of $R_{\mathrm{MoSi}_{2}}$ and that the $\mathrm{Al}_{2} \mathrm{O}_{3}$ shell has a uniform thickness of $\delta_{\mathrm{Al}_{2} \mathrm{O}_{3}}$ (the inset in Fig.5). The total volume of the healing particle after 
encapsulation, $V_{\text {Particle }}$, is made up of the volume of the $\mathrm{MoSi}_{2}$ core, $V_{\mathrm{MoSi}_{2}}$, and the volume of the $\mathrm{Al}_{2} \mathrm{O}_{3}$ shell, $V_{\mathrm{Al}_{2} \mathrm{O}_{3}}$, which can be described as:

$$
V_{\text {Particle }}=V_{\mathrm{MoSi}_{2}}+V_{\mathrm{Al}_{2} \mathrm{O}_{3}}
$$

$V_{\mathrm{Particle}}$ and $V_{\mathrm{MoSi}_{2}}$ are given by (neglecting the volume change associated with Al depletion during encapsulation):

$$
\begin{gathered}
V_{\text {Particle }}=\frac{4}{3} \pi\left(R_{\mathrm{MoSi}_{2}}+\delta_{\mathrm{Al}_{2} \mathrm{O}_{3}}\right)^{3} \\
V_{\mathrm{MoSi}_{2}}=\frac{4}{3} \pi R_{\mathrm{MoSi}_{2}}^{3}
\end{gathered}
$$

If all $\mathrm{Al}$ alloyed in the particle is consumed during encapsulation, $V_{\mathrm{Al}_{2} \mathrm{O}_{3}}$ is given by:

$$
V_{\mathrm{Al}_{2} \mathrm{O}_{3}}=\frac{4}{3} \pi R_{\mathrm{MoSi}_{2}}^{3} \frac{x \rho_{\mathrm{MoSi}_{2}}}{2 M_{\mathrm{Al}}} \frac{M_{\mathrm{Al}_{2} \mathrm{O}_{3}}}{\rho_{\mathrm{Al}_{2} \mathrm{O}_{3}}}
$$

where $\rho_{\mathrm{MoSi}_{2}}$ and $\rho_{\mathrm{Al}_{2} \mathrm{O}_{3}}$ is the density of the $\operatorname{MoSi}_{2}\left(6.26 \mathrm{~g} / \mathrm{cm}^{3}{ }^{30}\right)$ and $\mathrm{Al}_{2} \mathrm{O}_{3}\left(3.95 \mathrm{~g} / \mathrm{cm}^{3}\right)$; $M_{\mathrm{Al}}$ and $M_{\mathrm{Al}_{2} \mathrm{O}_{3}}$ are molar mass of $\mathrm{Al}(26.98 \mathrm{~g} / \mathrm{mol})$ and $\mathrm{Al}_{2} \mathrm{O}_{3}(101.96 \mathrm{~g} / \mathrm{mol}) ; x$ is the weight percentage of $\mathrm{Al}$ in the particle (12 wt\%).

Combining Eqs (1-4) yields

$$
\frac{4}{3} \pi\left(R_{\mathrm{MoSi}_{2}}+\delta_{\mathrm{Al}_{2} \mathrm{O}_{3}}\right)^{3}=\frac{4}{3} \pi R_{\mathrm{MoSi}_{2}}^{3}+\frac{4}{3} \pi R_{\mathrm{MoSi}_{2}}^{3} \frac{x \rho_{\mathrm{MoSi}_{2}}}{2 M_{\mathrm{Al}}} \frac{M_{\mathrm{Al}_{2} \mathrm{O}_{3}}}{\rho_{\mathrm{Al}_{2} \mathrm{O}_{3}}}
$$

$\delta_{\mathrm{Al}_{2} \mathrm{O}_{3}}$ is then solved as:

$$
\delta_{\mathrm{Al}_{2} \mathrm{O}_{3}}=R_{\mathrm{MoSi}_{2}}\left[\left(1+\frac{x \rho_{\mathrm{MoSi}_{2}}}{2 M_{\mathrm{Al}}} \frac{M_{\mathrm{Al}_{2} \mathrm{O}_{3}}}{\rho_{\mathrm{Al}_{2} \mathrm{O}_{3}}}\right)^{\frac{1}{3}}-1\right]=0.108 R_{\mathrm{MoSi}_{2}}
$$

This article is protected by copyright. All rights reserved. 
According to Eq. (6), $\delta_{\mathrm{Al}_{2} \mathrm{O}_{3}}$ is proportional to $R_{\mathrm{MoSi}_{2}}$, as plotted in Fig.5. For the healing particle shown in Fig.3a, the radius is approximately $3.3 \mu \mathrm{m}$, which yields $\delta_{\mathrm{Al}_{2} \mathrm{O}_{3}} \approx 350 \mathrm{~nm}$. This is more or less in agreement with the thickness of the $\mathrm{Al}_{2} \mathrm{O}_{3}$ shell observed in Fig.3a.

\subsection{Evolution of embedded healing particles upon thermal cycling}

The SEM observations and EDS analysis of the healing particles during thermal cycling are shown in Fig.6. It is seen that a $\mathrm{SiO}_{2}$ layer (confirmed by the EDS point analysis) develops between the $\mathrm{MoSi}_{2}$ core and the $\mathrm{Al}_{2} \mathrm{O}_{3}$ shell, and the $\mathrm{SiO}_{2}$ layer thickens with thermal cycling, as quantified by image analysis and plotted in Fig.6i. The morphology of the particles suggests that they have not been intersected by cracks in the topcoat matrix, which rules out the possibility that the oxidation of the particles is associated with crack healing. The observations suggest that despite being protected by the $\mathrm{Al}_{2} \mathrm{O}_{3}$ shell, oxidation of $\mathrm{MoSi}_{2}$ core still occurs during thermal cycling. As a result of the Si depletion during thermal cycling because of oxidation, the $\mathrm{MoSi}_{2}$ cores were gradually transformed to $\mathrm{Mo}_{5} \mathrm{Si}_{3}$. The transformation starts near the $\mathrm{SiO}_{2} / \mathrm{MoSi}_{2}$ interface and gradually advances into the inner part of the core until the $\mathrm{MoSi}_{2}$ core is fully converted to $\mathrm{Mo}_{5} \mathrm{Si}_{3}$, which can be seen in the healing particle after 240 cycles; see Fig.6c. Internal oxidation of Si is observed in the particle core after 400 cycles (see Fig.6d), suggesting that the outward diffusion of Si is not quick enough to reach the interface to form external $\mathrm{SiO}_{2}$.

In theory, if the $\mathrm{Al}_{2} \mathrm{O}_{3}$ shell around the $\mathrm{MoSi}_{2}$ core is perfectly intact and continuous, the oxygen partial pressure at the interface between the $\mathrm{MoSi}_{2}$ core and the $\mathrm{Al}_{2} \mathrm{O}_{3}$ shell would be governed by the dissociation partial pressure of $\alpha-\mathrm{Al}_{2} \mathrm{O}_{3}\left(\sim 10^{-34}\right.$ atm. at $1100{ }^{\circ} \mathrm{C}$ in thermodynamic equilibrium, determined from Ellingham diagrams ${ }^{31}$ ). Unless cracking of the $\mathrm{Al}_{2} \mathrm{O}_{3}$ shell occurs (which is possible during extensive thermal cycling), oxidation of $\mathrm{MoSi}_{2}$ 
and subsequent development of a $\mathrm{SiO}_{2}$ layer between the $\mathrm{MoSi}_{2}$ core and the $\mathrm{Al}_{2} \mathrm{O}_{3}$ shell (which requires $\sim 10^{-23}$ atm at $1100{ }^{\circ} \mathrm{C}$ in thermodynamic equilibrium, determined from Ellingham diagrams ${ }^{31}$ ) would thermodynamically be prevented. However, the TEM analysis (Fig.4) shows that there are many nanoscale YSZ inclusions in the $\mathrm{Al}_{2} \mathrm{O}_{3}$ shell. The presence of these fine YSZ inclusions compromises the protectiveness of the $\mathrm{Al}_{2} \mathrm{O}_{3}$ shell by enhancing the oxygen diffusivity through the shell and increasing the oxygen partial pressure at the interface, thereby causing oxidation of the internal $\mathrm{MoSi}_{2}$ core and subsequent growth of a $\mathrm{SiO}_{2}$ layer between the $\mathrm{MoSi}_{2}$ core and the $\mathrm{Al}_{2} \mathrm{O}_{3}$ shell.

TEM analysis of a healing particle after 160 cycles is shown in Fig.7. In agreement with the SEM observations (see Fig.6), the HAADF-STEM image (Fig.7a) and the corresponding EDS analysis (Fig.7d-g) further confirm the formation of a $\mathrm{SiO}_{2}$ layer ( $800 \mathrm{~nm}$ thick) between the intermetallic core and the $\mathrm{Al}_{2} \mathrm{O}_{3}$ shell. SAED analysis of the $\mathrm{SiO}_{2}$ layer shows a diffraction halo (see Fig.7c), suggesting that the $\mathrm{SiO}_{2}$ is amorphous. The glassy nature of the $\mathrm{SiO}_{2}$ layer is further confirmed by the absence of any band contrast during the TKD scan (see Fig.7b). It is worth mentioning that the capability to develop amorphous $\mathrm{SiO}_{2}$ is essential to the realisation of crack healing as the healing mechanism relies on the ability of $\mathrm{SiO}_{2}$ to flow into the cracks and react with YSZ to seal the cracks, which otherwise could not be fulfilled by crystallised $\mathrm{SiO}_{2}$ counterparts.

The combined TKD band contrast and phase map shows that the $\mathrm{Al}_{2} \mathrm{O}_{3}$ shell is of exclusively composed of $\alpha-\mathrm{Al}_{2} \mathrm{O}_{3}$ grains with $\mathrm{YSZ}$ and $\mathrm{ZrSiO}_{4}$ inclusions (see Fig.7b). Formation of zircon is also seen at the interface between the $\mathrm{Al}_{2} \mathrm{O}_{3}$ shell and the $\mathrm{YSZ}$ matrix, indicating that the shell does not offer sufficient protection against premature oxidation. This is likely due to the many YSZ inclusions in the original $\mathrm{Al}_{2} \mathrm{O}_{3}$ shell (see Figs 3 and 4). Then, oxygen can penetrate through the shell and reacts with the core of the particle forming $\mathrm{SiO}_{2}$. The volume expansion associated with the silica formation may have caused cracking of the shell 
and the $\mathrm{SiO}_{2}$ subsequently flows through the cracks and reacts with the YSZ matrix to form $\mathrm{ZrSiO}_{4}$. Also, the flowing $\mathrm{SiO}_{2}$ can react with the exposed YSZ inclusions and form zircon grains embedded in the $\mathrm{Al}_{2} \mathrm{O}_{3}$ shell.

Cracking is hardly seen at the interface between the healing particle and YSZ topcoat matrix, suggesting that there is a strong bonding between these two materials. This observation is important as a strong particle/matrix interface is necessary for crack to propagate into the healing particles and triggering of the crack healing reaction. A weak particle/matrix interface would promote crack propagation along the particle/matrix interface, i.e. delamination, leaving the particle shielding intact which would delay the onset of the healing reaction.

No mullite phase has been identified at the interface between the $\mathrm{Al}_{2} \mathrm{O}_{3}$ shell and the $\mathrm{SiO}_{2}$ layer, suggesting that these two materials are thermodynamically compatible with each other under the thermal exposure conditions used this study. The finding is also important because, although the $\mathrm{Al}_{2} \mathrm{O}_{3}$ shell could not fully prevent the $\mathrm{MoSi}_{2}$ core from being oxidised, the persistence of this stable $\mathrm{Al}_{2} \mathrm{O}_{3}$ shell can act as a physical barrier to avoid direct contact between the $\mathrm{SiO}_{2}$ and YSZ topcoat matrix. The separation prevents premature filling of the pre-existing porosities and microcracks in the topcoat by $\mathrm{SiO}_{2}$, which are essential to the strain tolerance of the topcoat and the durability of the TBCs.

\subsection{Effect of oxidation of healing particles on crack healing and TBC degradation}

The delayed yet premature oxidation of the Al-containing $\mathrm{MoSi}_{2}$ particles and the associated Si depletion of the particle core could undermine the realisation of crack healing during longterm thermal cycling. Specifically, to achieve successful crack healing and maximise the healing efficiency, it is essential that when a crack propagates into the healing particle, a sufficient amount of $\mathrm{SiO}_{2}$ could form to fill the free space created by the crack. The depletion 
of $\mathrm{Si}$ associated with the premature oxidation of the particles will reduce the amount of $\mathrm{Si}$ available for oxidation and therefore could lower the crack healing efficiency. For instance, calculations based on oxidation reaction formula show that the volume expansion associated with the conversion of $\mathrm{MoSi}_{2}$ to $\mathrm{SiO}_{2}\left(2 \mathrm{MoSi}_{2}+7 \mathrm{O}_{2}=2 \mathrm{MoO}_{3} \uparrow+4 \mathrm{SiO}_{2}\right)$ is $138 \%$, but the volume expansion associated with the conversion of $\mathrm{Mo}_{5} \mathrm{Si}_{3}$ to $\mathrm{SiO}_{2}$ $\left(2 \mathrm{Mo}_{5} \mathrm{Si}_{3}+21 \mathrm{O}_{2}=10 \mathrm{MoO}_{3} \uparrow+6 \mathrm{SiO}_{2}\right)$ is only $19 \%$. On the other hand, the continuous depletion of $\mathrm{Si}$ in the healing particle could shift its composition to a range that growth of an external $\mathrm{SiO}_{2}$ scale is no longer kinetically favoured. Under this circumstance, internal oxidation could occur, as exemplified in Fig.6g. This is also undesirable to crack healing, which requires $\mathrm{SiO}_{2}$ to form externally on the crack planes and infiltrate the crack.

Apart from the detrimental effect on crack healing, the premature oxidation of the healing particle also affects the degradation and failure of the TBCs. Our observations show that edge delamination is the predominant failure mechanism of the self-healing APS TBCs during thermal cycling, as shown in Fig.8. The edge delamination is initially manifested as lateral cracking at the base of the topcoat, followed by lift-off of the detached topcoat edge and vertical cracking near the fixed end. Premature oxidation of the healing particles is related to the observations in two ways. First, as $\mathrm{SiO}_{2}$ has an extremely low $\mathrm{CTE}\left(\sim 0.55 \times 10^{-6} /{ }^{\circ} \mathrm{C}\right){ }^{32}$, excessive oxidation of the healing particles raises the level of thermal stress in the topcoat and increase the driving force for edge delamination. Second, the premature oxidation also creates mismatch between the upper part of the topcoat (without healing particles) and the lower part of the topcoat (with healing particles), which drives deformation and vertical cracking of the detached coating edge. This argument could be illustrated from the following two aspects. First, the volume expansion associated with the oxidation of the healing particles leads to lateral swelling of the lower part of the topcoat and subsequent bending of the free end of the detached topcoat away from the interface. Second, due to the higher CTE of the 
upper part of the topcoat, this part of the topcoat undergoes more thermal contraction during cooling, causing the unattached topcoat to further bend away from the substrate. The bending creates a tensile stress at the bottom of the unattached coating edge near the fixed end and this leads to subsequent vertical cracking. It is expected that when the unattached coating edge spalls off, a new edge will be created and the edge delamination process described above will repeat itself.

\subsection{Experimental evidence of cracking healing}

Although the crack healing mechanism in the self-healing TBC system has been rationalised in theory ${ }^{33}$, unambiguous experimental evidence showing crack healing in real self-healing APS TBCs has not been reported yet. Fig.9a shows a healing particle cut through by a crack from the topcoat matrix near the topcoat/bond coat interface after 320 cycles. It should be noted that the two remaining intermetallic cores in Fig.9a originally belong to the same healing particle. This argument is supported by the EDS analysis (see Fig.9b) showing that the two cores are encompassed by a single $\mathrm{Al}_{2} \mathrm{O}_{3}$ shell (otherwise, two independent $\mathrm{Al}_{2} \mathrm{O}_{3}$ shells would be detected by EDS). In accompany with the breaking of the healing particle, substantial oxidation has occurred at the crack planes within the particle.

Following the path of the through-particle crack, signs of crack healing are identified in some areas outside the healing particle (marked by the red circle in Fig. 9a). EDS analysis over these areas shows the presence of $\mathrm{Si}$, but did not reveal any aluminium (Fig.9b and c). This finding is important for two reasons. First, it excludes the possibility that the Si is from any other pre-existing healing particles in these areas (otherwise, $\mathrm{Al}_{2} \mathrm{O}_{3}$ shells would be detected).

Second, it confirms that when the healing particle is opened by a crack, the $\mathrm{SiO}_{2}$ developed during oxidation can flow through the crack and fill the crack gap in the topcoat matrix. EDS 
point analysis suggests that the $\mathrm{Zr} / \mathrm{Si}$ ratio in the crack healing area is approximately 1 , suggesting the formation of the $\mathrm{ZrSiO}_{4}$. Summarising, the observations are in good agreement with envisaged self-healing mechanism proposed 6,7 . It is worth mentioning that the occurrence of crack healing does not necessarily mean that the entire crack will be completely healed or the sealed crack will no longer undergo re-cracking during subsequent long-term thermal cycling. It is possible that the empty volume between the crack planes exceeds the volume of the healing particles in direct contact with the crack and therefore only a part of the crack is healed. On the other hand, it is also possible that the repeated thermomechanical loading during extensive thermal cycling gives rise to sufficient strain to open the healed crack. Either of the two mechanisms can be the reason for the observed crack propagation outside the crack healing zone (the red circle in Fig.9a).

It might be argued that it is still unclear if the through-particle crack as seen in Fig.9a is caused by crack propagation from the topcoat into the healing particle or is the result of cracking of the healing particle itself, which then propagates into the topcoat. The latter case certainly does not agree with the self-healing concept. Indeed, while $\mathrm{MoSi}_{2}$ shows a substantial ductility at high temperatures (e.g. above $900{ }^{\circ} \mathrm{C}{ }^{34-36}$ ), it has a relatively low toughness and limited ductility at room temperature ${ }^{34-36}$, which makes fracture of the particle possible if it was under tensile stress at room temperature. To clarify this issue, it would be helpful to evaluating the stress state of the particle during thermal cycling.

Here a spherical $\mathrm{MoSi}_{2}$ particle embedded in an YSZ topcoat matrix is considered. Assumed that both materials are stress free during dwelling at $1100{ }^{\circ} \mathrm{C}$ as any stress generated (e.g. stress caused by volume expansion associated with oxidation) could be relaxed by creep. Also assumed that no creep or cracking occurs in either material or at the interface and any creep relaxation during cooling is neglected. Then the stress in the spherical inclusion induced by thermal mismatch then can be estimated by ${ }^{37}$ : 


$$
\sigma_{r r}=\sigma_{\theta \theta}=\frac{2 E_{\text {Matrix }} E_{\text {MoSi }_{2}}\left(\alpha_{\text {Matrix }}-\alpha_{M_{\text {oSi }}}\right)\left(T_{A}-T_{0}\right)}{2 E_{\text {Matrix }}\left(1-v_{M_{\text {oSi }}}\right)+E_{\text {MoSi }_{2}}\left(1+v_{\text {Matrix }}\right)}
$$

Where $E$ is Young's modulus $E_{\text {Matrix }}=50 \mathrm{GPa}$ (as determined by micro-indentation) and $\left.E_{\mathrm{MoSi}_{2}}=430 \mathrm{GPa}{ }^{38}\right) ; \alpha$ is the $\mathrm{CTE}\left(\alpha_{Y S Z}=10.5 \times 10^{-6} /{ }^{\circ} \mathrm{C}{ }^{39}\right.$ and $\alpha_{\mathrm{MoSi}_{2}}=8.1 \times$ $\left.10^{-6} /{ }^{\circ} \mathrm{C}^{40}\right) ; T_{0}$ is the peak temperature during thermal cycling $\left(1100{ }^{\circ} \mathrm{C}\right)$ and $T_{A}$ is the ambient temperature $\left(20{ }^{\circ} \mathrm{C}\right) ; v$ is Poisson ratio $\left(v_{\text {Matrix }}=0.3\right.$ and $\left.v_{\mathrm{MoSi}_{2}}=0.16^{38}\right)$. Then, calculation based on Eq. (7) shows that the healing particle is in a state of hydro-static compression of about $170 \mathrm{MPa}$ upon cooling. This compressive stress is expected to inhibit internal cracking of the particle during thermal cycling. As a result, it is believed that the through-particle crack observed in Fig. 9a is indeed the result of crack propagation from the topcoat matrix into the healing particles, which subsequently runs through the particle and triggers the crack healing mechanism.

Finally, our observations also show that whether a growing crack in the topcoat cuts into a healing particle or is deflected away from the particle also depends on the shape of the particle. Crack healing is more likely to occur for rod-shaped particles with their long-axis perpendicular to interface (e.g. Fig.9a). In contrast, crack healing has not been seen for particles with the characteristic "splat" shape. The observations are schematically summarised in Fig. 10.

In theory, when a crack intercepts a microstructural heterogeneity (in this case, a second phase particle), the local Mode I stress intensity factor at the crack tip for the crack to deflect away from the interface, $K_{I}^{t}$, is given by ${ }^{41}$ :

$$
K_{I}^{t}=\left(\cos \frac{\theta}{2}\right)^{3} K_{I}
$$

where $K_{I}$ is the stress intensity factor of the impinging crack and $\theta$ is the tilt angle between the deflected crack plane and the original crack plane. For a given $K_{I}, \theta$ would be much This article is protected by copyright. All rights reserved. 
larger for a rod-shaped healing particle than that for a splat-shaped particle, resulting in a much lower driving force for crack deflection when the crack intercepts a rod-shaped particle. Optimisation of the shape of the healing particles may be needed in the future as many healing particles in the self-healing APS TBCs show characteristic splat microstructure (see Fig.1), which is nevertheless undesirable for crack healing. A more detailed micromechanical study on the effect of the particle shape and its orientation on its cracking tendency during thermal cycling is ongoing.

\section{Conclusion}

$\mathrm{MoSi}_{2}$ particles containing $12 \mathrm{wt} \%$ aluminium are integrated as healing particles into an APS produced thermal barrier coating. Due to selective oxidation a $500 \mathrm{~nm} \mathrm{Al}{ }_{2} \mathrm{O}_{3}$ layer is formed at the particle-TBC matrix interface during the pre-oxidative treatment. Nevertheless, it is shown that the $\mathrm{MoSi}_{2}$ healing particles undergo premature oxidation during subsequent thermal cycling despite being protected by the $\mathrm{Al}_{2} \mathrm{O}_{3}$ shell. The imperfect protection is attributed to the large number of nanoscale YSZ inclusions in the $\mathrm{Al}_{2} \mathrm{O}_{3}$ shell, which facilitate oxygen diffusion through the shells. The premature oxidation of the healing particles undermines the crack healing capability during long-term thermal exposure and affects degradation of the self-healing APS TBCs. Crack healing has been identified in the selfhealing APS TBCs, which is agreement with the envisaged crack healing mechanism.

\section{Acknowledgements}

This project has received funding from European Union Seventh Framework Program (FP7/2007-2013) under grant agreement no. 309849, SAMBA (website: www.sambaproject.eu). The authors acknowledge many fruitful discussions with the SAMBA This article is protected by copyright. All rights reserved. 
project partners and in particular Prof. Robert Vaßen and his team at Forschungszentrum

Jülich (Germany) for sample preparation using their optimised APS set-up.

\section{References}

1. Evans AG, Mumm DR, Hutchinson JW, Meier GH, Pettit FS. Mechanisms controlling the durability of thermal barrier coatings. Prog Mater Sci. 2001;46(5):505-553.

2. Padture NP, Gell M, Jordan EH. Thermal Barrier Coatings for Gas-Turbine Engine Applications. Science. 2002;296(5566):280.

3. Miller RA. Current status of thermal barrier coatings - An overview. Surf Coat Technol. 1987;30(1):1-11.

4. Vaßen R, Kerkhoff G, Stöver D. Development of a micromechanical life prediction model for plasma sprayed thermal barrier coatings. Mater Sci Eng, A. 2001;303(1):100-109.

5. Schlichting KW, Padture NP, Jordan EH, Gell M. Failure modes in plasma-sprayed thermal barrier coatings. Mater Sci Eng, A. 2003;342(1):120-130.

6. Derelioglu Z, Carabat AL, Song GM, van der Zwaag S, Sloof WG. On the use of B-alloyed $\mathrm{MoSi} 2$ particles as crack healing agents in yttria stabilized zirconia thermal barrier coatings. J Eur Ceram Soc. 2015;35(16):4507-4511.

7. Sloof WG, Turteltaub SR, Carabat AL, Derelioglu Z, Ponnusami SA. Crack healing in yttria stabilized zirconia thermal barrier coatings. In: Van der Zwaag S, Brinkman E, editors. Self Healing Materials - Pioneering Research in the Netherlands: IOS Press under the imprint Delft University Press; 2015. p. 219-227.

8. Kochubey V, Sloof WG. Self healing mechanism in thermal barrier coatings. In: Lugscheider E, editor. ITSC 2008: International Thermal Spray Conference and Exposition; 2008-07-01; Maastricht (Netherlands). Deutscher Verband fuer Schweisstechnik e.V. (DVS), Duesseldorf (Germany): DVS-Verlag, Duesseldorf (Germany); 2008.

9. McEvoy AJ. Thin SOFC electrolytes and their interfaces-: A near-term research strategy. Solid State Ionics. 2000;132(3):159-165.

10. Skinner SJ, Kilner JA. Oxygen ion conductors. Mater Today. 2003;6(3):30-37.

11. Heuer AH. Oxygen and aluminum diffusion in $\alpha$-A12O3: How much do we really understand? J Eur Ceram Soc. 2008;28(7):1495-1507.

12. Oishi Y, Kingery WD. Self- Diffusion of Oxygen in Single Crystal and Polycrystalline Aluminum Oxide. J Chem Phys. 1960;33(2):480-486.

13. Clarke DR, Levi CG. Materials Design for the Next Generation Thermal Barrier Coatings. Annu Rev Mater Res. 2003;33(1):383-417.

14. Carabat AL, Zwaag S, Sloof WG. Creating a Protective Shell for Reactive MoSi2 Particles in High-Temperature Ceramics. J Am Ceram Soc. 2015;98(8):2609-2616.

15. Carabat AL, Meijerink MJ, Brouwer JC, Kelder EM, van Ommen JR, van der Zwaag S, Sloof WG. Protecting the MoSi2 healing particles for thermal barrier coatings using a sol-gel produced Al2O3 coating. J Eur Ceram Soc. 2018;38(7):2728-2734.

16. Nozahic F, Estournès C, Carabat AL, Sloof WG, van der Zwaag S, Monceau D. Self-healing thermal barrier coating systems fabricated by spark plasma sintering. Mater Des. 2018;143:204-213.

17. Koch D, Mauer G, Vaßen R. Manufacturing of Composite Coatings by Atmospheric Plasma Spraying Using Different Feed-Stock Materials as YSZ and MoSi2. J Therm Spray Technol. 2017;26(4):708-716.

18. Kulczyk-Malecka J, Zhang X, Carr J, Carabat AL, Sloof WG, van der Zwaag S, Cernuschi F, Nozahic F, Monceau D, Estournès C, Withers PJ, Xiao P. Influence of embedded MoSi2 particles on the high temperature thermal conductivity of SPS produced yttria-stabilised zirconia model thermal barrier coatings. Surf Coat Technol. 2016;308:31-39.

This article is protected by copyright. All rights reserved. 
19. Kulczyk-Malecka J, Zhang X, Carr J, Nozahic F, Estournès C, Monceau D, Carabat AL, Sloof WG, van der Zwaag S, Withers PJ, Xiao P. Thermo - mechanical properties of SPS produced self-healing thermal barrier coatings containing pure and alloyed MoSi2 particles. J Eur Ceram Soc. 2018;38(12):4268-4275.

20. Mao W, Sloof WG. Reduction Kinetics of Wüstite Scale on Pure Iron and Steel Sheets in Ar and H2 Gas Mixture. Metallurgical and Materials Transactions B. 2017;48(5):2707-2716.

21. Chen L, Gao L, Yang G. Imaging Slit Pores Under Delaminated Splats by White Light Interference. J Therm Spray Technol. 2018;27(3):319-335.

22. Chen L, Yang G, Li C. Formation of Lamellar Pores for Splats via Interfacial or Subinterfacial Delamination at Chemically Bonded Region. J Therm Spray Technol. 2017;26(3):315-326.

23. Chen L, Yang G, Li C, Li C. Edge Effect on Crack Patterns in Thermally Sprayed Ceramic Splats. J Therm Spray Technol. 2017;26(3):302-314.

24. Kilo M, Argirusis C, Borchardt G, Jackson RA. Oxygen diffusion in yttria stabilised zirconia-experimental results and molecular dynamics calculations. Phys Chem Chem Phys. 2003;5(11):2219-2224.

25. Langford RM, Petford-Long AK. Preparation of transmission electron microscopy crosssection specimens using focused ion beam milling. J Vac Sci Technol, A. 2001;19(5):2186-2193.

26. Garner A, Gholinia A, Frankel P, Gass M, MacLaren I, Preuss M. The microstructure and microtexture of zirconium oxide films studied by transmission electron backscatter diffraction and automated crystal orientation mapping with transmission electron microscopy. Acta Mater. 2014;80:159-171.

27. Levi CG, Sommer E, Terry SG, Catanoiu A, Rühle M. Alumina Grown during Deposition of Thermal Barrier Coatings on NiCrAlY. J Am Ceram Soc. 2004;86(4):676-685.

28. Stiger MJ, Yanar NM, Jackson RW, Laney SJ, Pettit FS, Meier GH, Gandhi AS, Levi CG. Development of Intermixed Zones of Alumina/Zirconia in Thermal Barrier Coating Systems. Metall Mater Trans A. 2007;38(4):848-857.

29. Murphy KS, More KL, Lance MJ. As-deposited mixed zone in thermally grown oxide beneath a thermal barrier coating. Surf Coat Technol. 2001;146-147:152-161.

30. Nørlund Christensen A. Crystal growth and characterization of the transition metal silicides MoSi2 and WSi2. J Cryst Growth. 1993;129(1):266-268.

31. Gaskell DR. Introduction to Thermodynamics of Materials. 3RD ed. Washington, D.C: Taylor \& Francis; 1995.

32. Fused Silica, $\mathrm{SiO} 2$ Glass Properties [Internet]. Available from: https://www.accuratus.com/fused.html.

33. Krishnasamy J, Ponnusami SA, Turteltaub S, van der Zwaag S. Modelling the fracture behaviour of thermal barrier coatings containing healing particles. Materials \& Design. 2018;157:7586.

34. Ito K, Matsuda K, Shirai Y, Inui H, Yamaguchi M. Brittle-ductile behavior of single crystals of MoSi2. Mater Sci Eng, A. 1999;261(1):99-105.

35. Evans DJ, Scheltens FJ, Woodhouse JB, Fraser HL. Deformation mechanisms in MoSi2 at temperatures above the brittle-to-ductile transition temperature I. Polycrystalline MoSi2. Philos Mag A. $1997 ; 75(1): 1-15$.

36. Wade RK, Petrovic JJ. Fracture Modes in MoSi2. J Am Ceram Soc. 1992;75(6):1682-1684.

37. Green DJ. An Introduction to the Mechanical Properties of Ceramics. Cambridge: Cambridge University Press; 1998.

38. Properties: Molybdenum Disilicide - AZoM [Internet]. Available from: https://www.azom.com/properties.aspx?ArticleID=512.

39. Cao XQ, Vassen R, Stoever D. Ceramic materials for thermal barrier coatings. J Eur Ceram Soc. 2004;24(1):1-10.

40. Vasudévan AK, Petrovic JJ. A comparative overview of molybdenum disilicide composites. Mater Sci Eng, A. 1992;155(1):1-17.

41. Cotterell B, Rice JR. Slightly curved or kinked cracks. Int J Fract. 1980;16(2):155-169.

This article is protected by copyright. All rights reserved. 


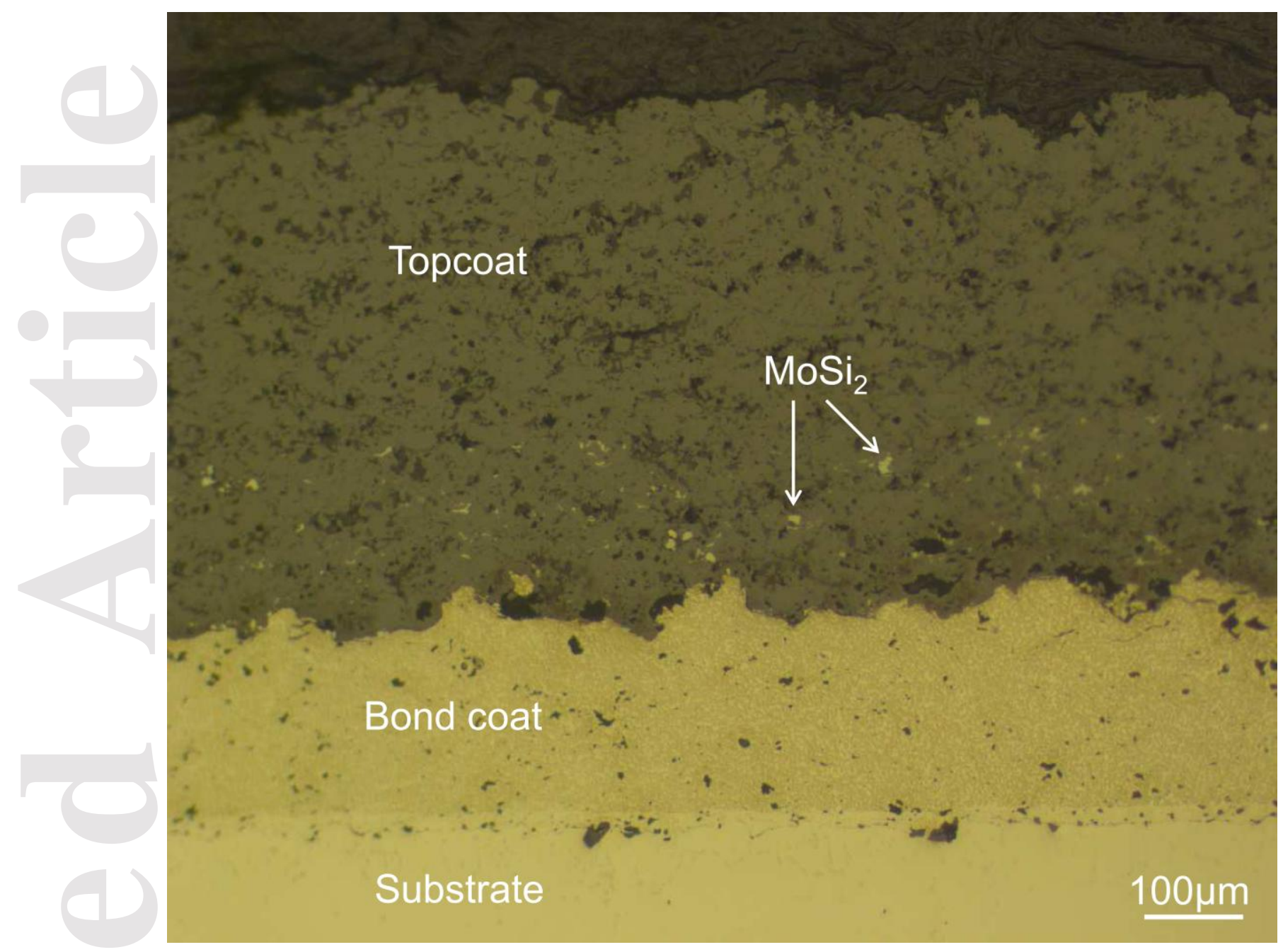

This article is protected by copyright. All rights reserved. 
Mo L $\alpha 1$
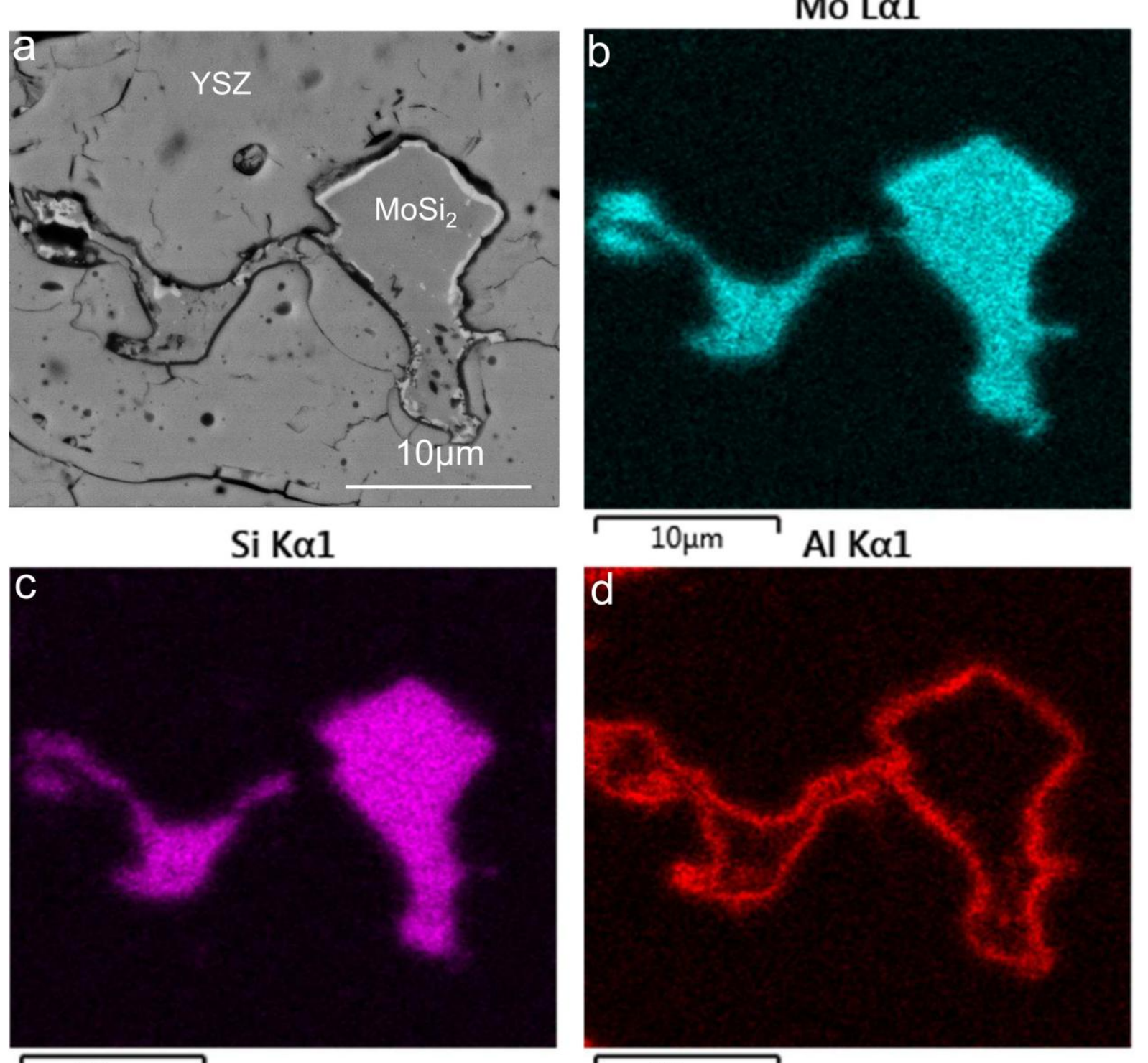

$10 \mu \mathrm{m}$

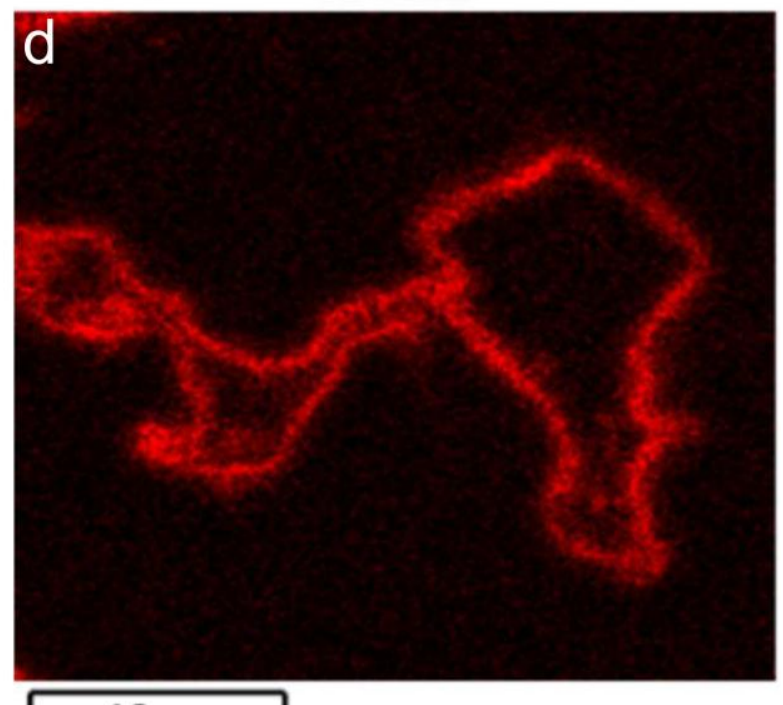

$10 \mu \mathrm{m}$

This article is protected by copyright. All rights reserved. 


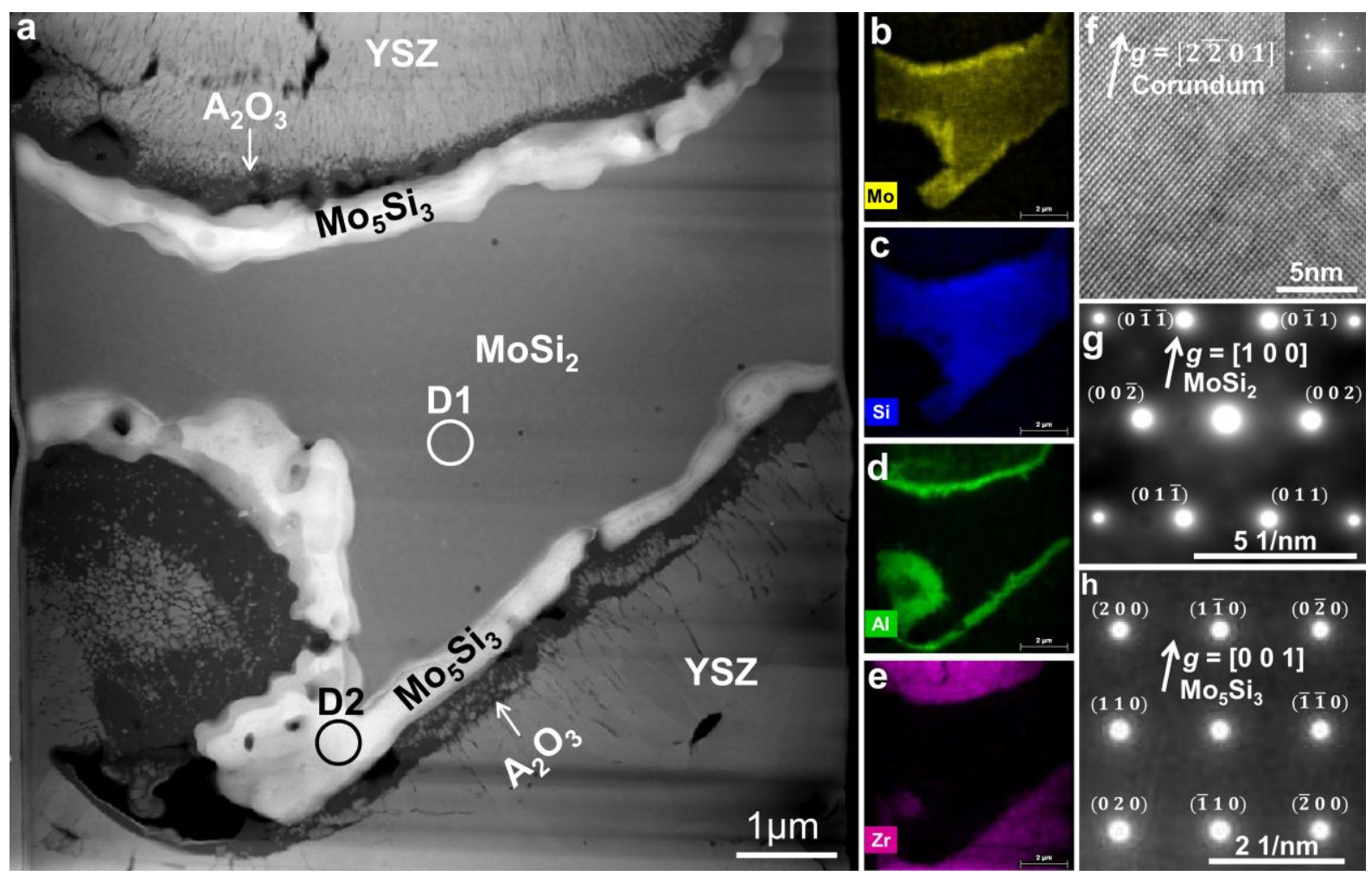

This article is protected by copyright. All rights reserved. 


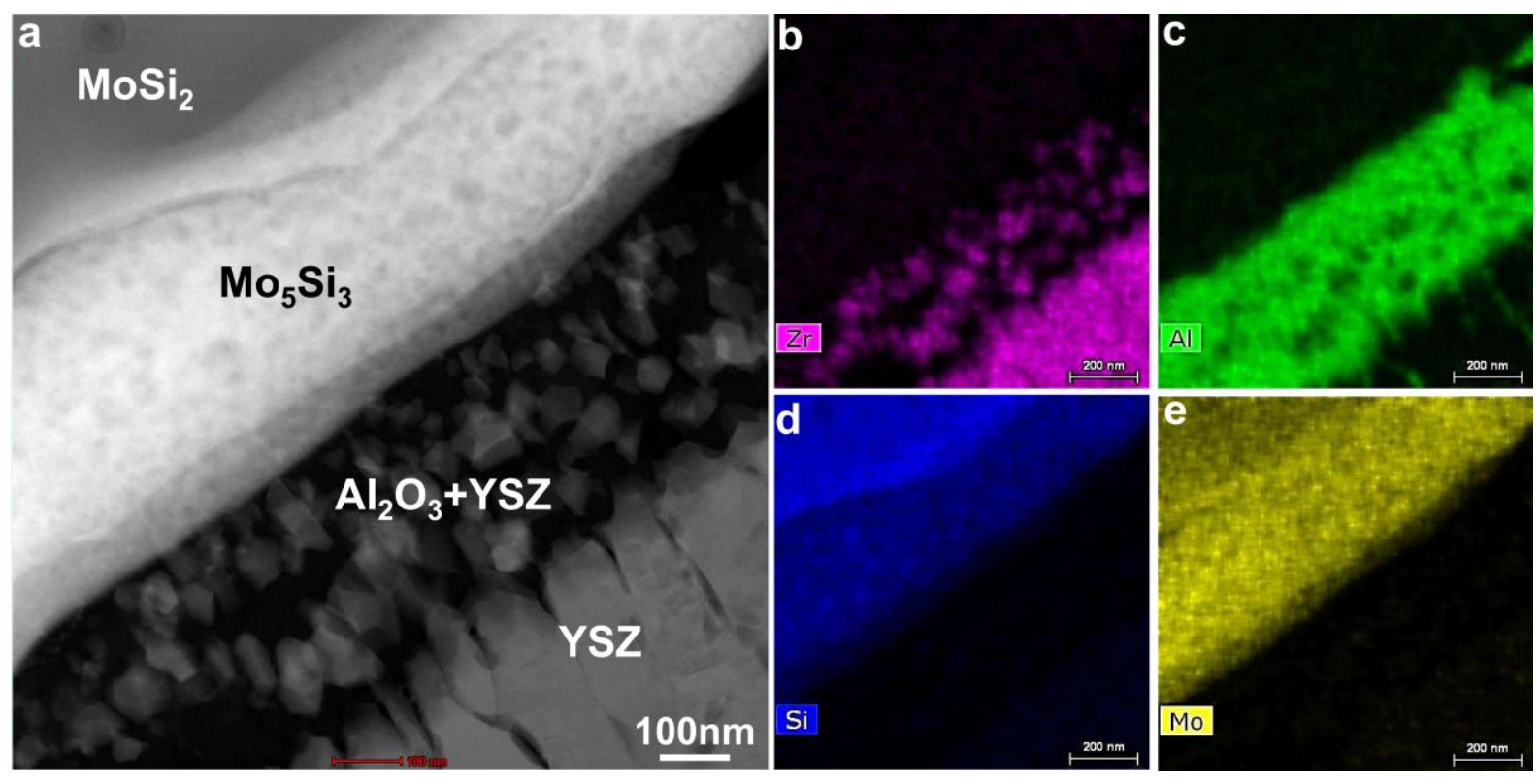

This article is protected by copyright. All rights reserved. 


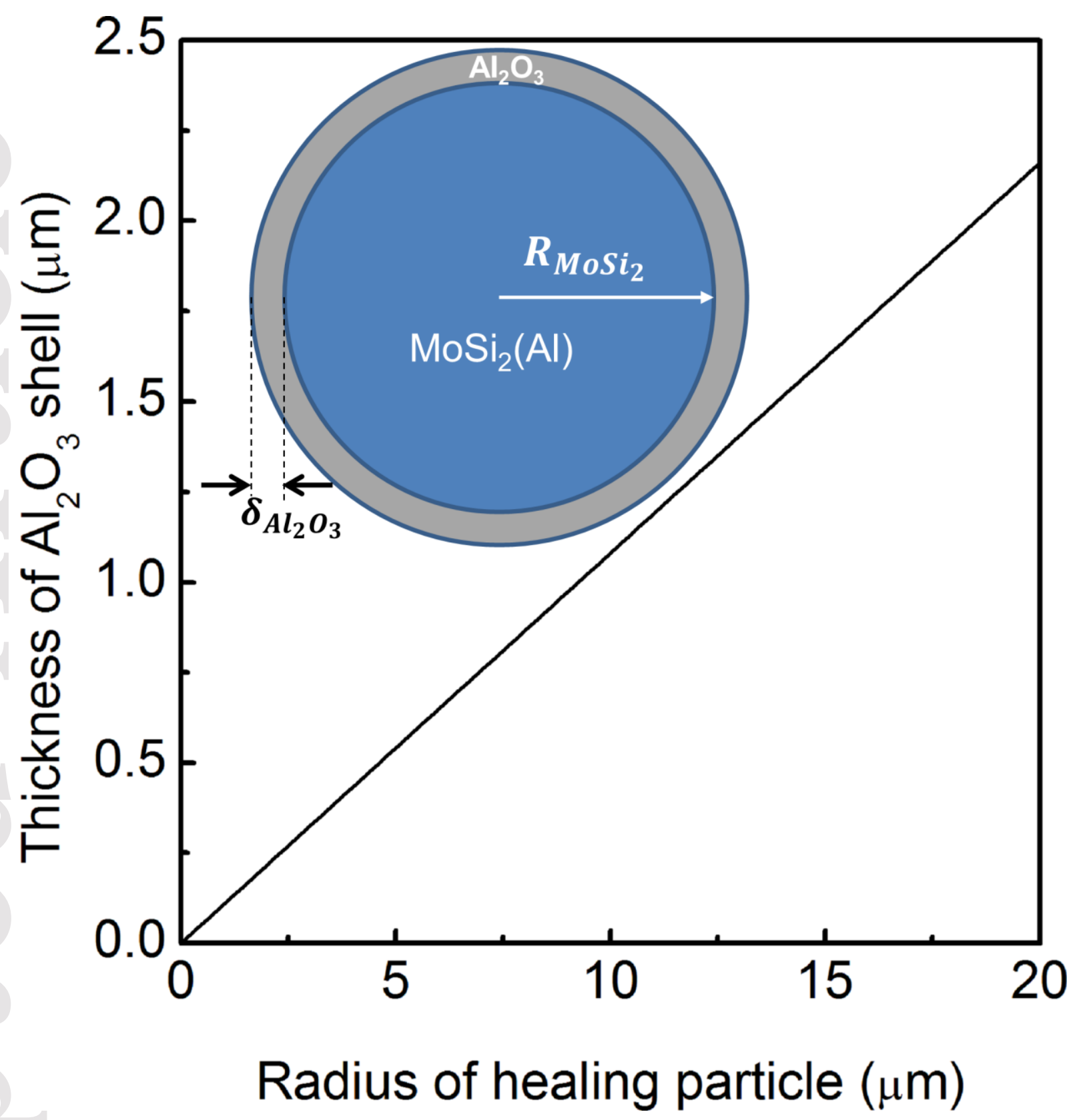

This article is protected by copyright. All rights reserved. 

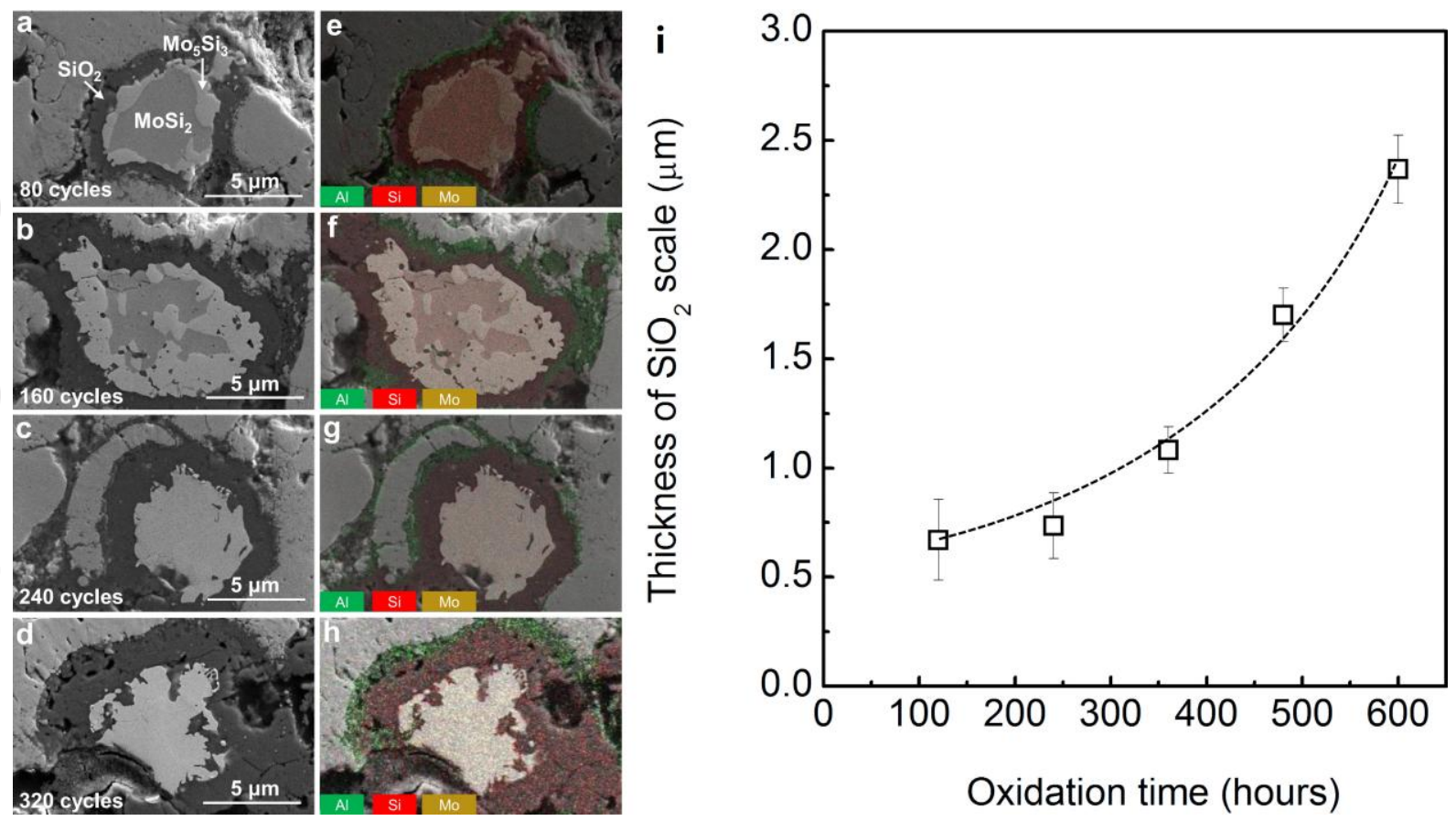

This article is protected by copyright. All rights reserved. 

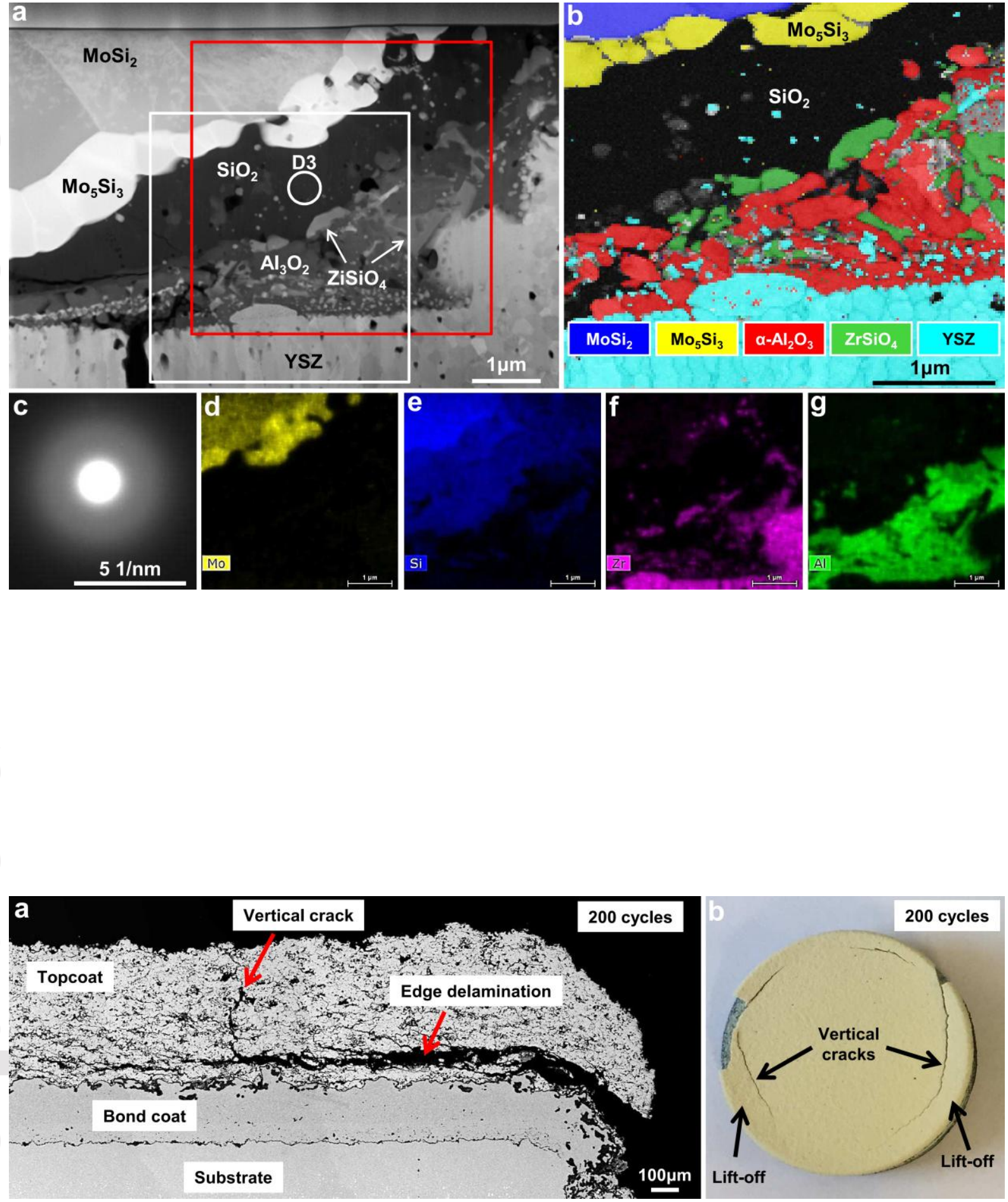

This article is protected by copyright. All rights reserved. 

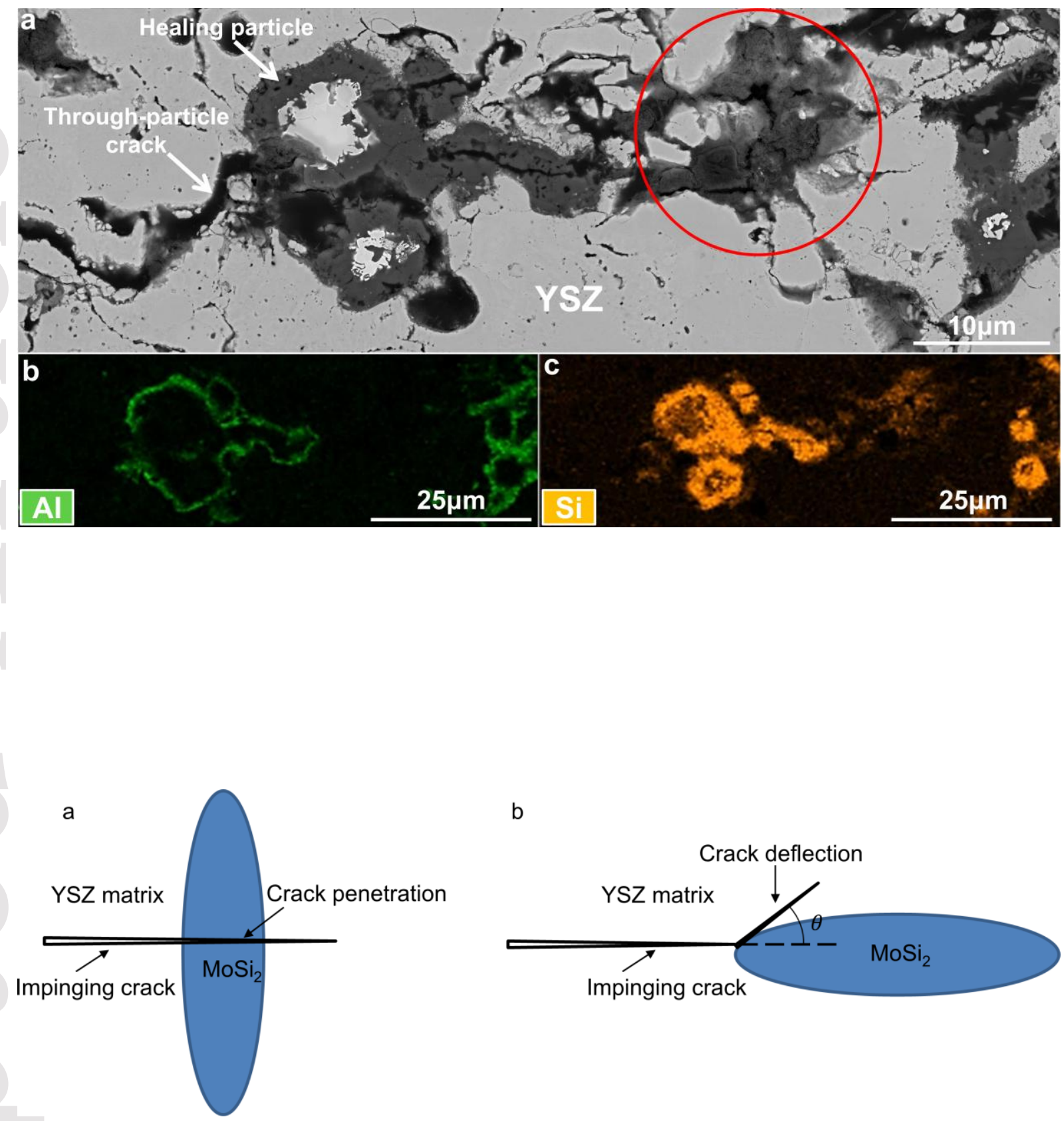

b

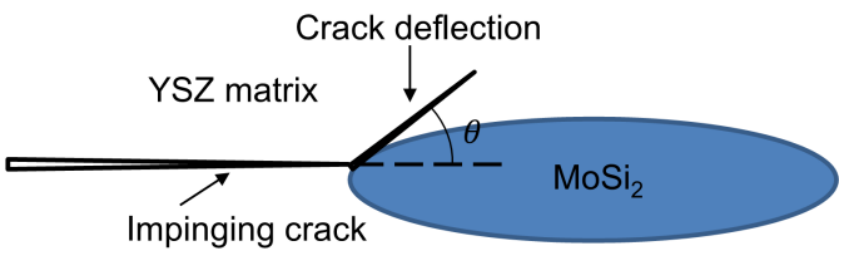

This article is protected by copyright. All rights reserved. 